\title{
Contribuição para o conhecimento das comunidades vegetais de Welwitschia mirabilis (Welwitschiaceae, Gnetophyta) do deserto do Namibe (Angola)
}

\author{
João Cardoso \\ Universidade José Eduardo dos Santos, (Angola) \\ João Paulo Fonseca \\ Carlos Neto \\ Centro de Estudos Geográficos. Instituto de Geografia \\ e Ordenamento Território, Universidade de Lisboa (Portugal)
}

Carlos Aguiar

CIMO-Centro de Investigação de Montanha, Instituto Politécnico de Bragança, (Portugal)

Frédéric Bioret

Géoarchitecture, UFR Sciences et Techniques, Université de Bretagne Occidentale (França)

José Carlos Costa

Instituto Superior de Agronomia, Universidade de Lisboa (Portugal)

DOI: https://doi.org/10.31492/2184-2043.RILP2018.35/pp.133-149

\section{Resumo}

A Welwitschia mirabilis é uma planta antiga, com uma morfologia e ecologia divergentes no âmbito das gimnospérmicas atuais. É endémica - e a espécie símbolo - do deserto do Namibe, o deserto mais antigo da Terra. Fazemos um estudo da estrutura florística e da sinecologia das comunidades vegetais W. mirabilis no território angolano. Concluímos existirem 4 comunidades distintas: (i) uma comunidade associada a linhas de água efémeras dominada por Acacia reficiens e Boscia pestalozziana; (ii) uma segunda comunidade, floristicamente pobre, dominada por W. mirabilis, de áreas secas e planas com sedimentos heterométricos nos interflúvios; (iii) uma terceira comunidade associada a sedimentos arenosos dominanda por gramíneas perenes; (iv) e, por último, uma comunidade dominada por espécies do género Commiphora (Burseraceae), própria dos sectores basais de inselbergs xistosos e/ou grauvaquicos.

Palavras-chave: Angola; Gnetophyta; deserto do Namibe; fitossociologia; Welwitschia mirabilis.

\section{Abstract}

Welwitschia mirabilis is an ancient plant with a divergent morphology and ecology from other gymnosperms. It is a symbol and an endemic species of the Namib Desert, the oldest desert on Earth. We studied the floristic structure, the phytosociology and synecology of the plant communities dominated by W. mirabilis in Angolan territory. We conclude that there are 4 distinct communities: (i) a community associated with ephemeral watercourses dominated by Acacia reficiens and Boscia pestalozziana; (ii) a second community, floristically 
poor, dominated by W. mirabilis, from dry and flat Interfluvial areas with heterometric sediments; (iii) a third community associated with sandy sediments dominated by perennial grasses; (iv) and a community dominated by Commiphora species (Burseraceae), typical of the basal sectors of schist or greywackes residual reliefs (inselbergs).

Keywords: Angola; ; Gnetophyta; Namib desert; phytosociology; Welwitschia mirabilis.

\section{Introdução}

A Welwitschia mirabilis Hooker f. (Welwitschiaceae) (Figura 1.) foi descoberta para a ciência em 1859, perto do Cabo Negro, a norte de Tômbua, em Angola, pelo naturalista austríaco Friedrich Welwitsch [1806-1872], então ao serviço da administração colonial portuguesa (Swinscow, 1972). Inicialmente descrita sob o nome Tumboa mirabilis, foi pouco depois renomeada em honra ao seu descobridor pelo botânico inglês Joseph D. Hooker (Hooker, 1862). A W. mirabilis é um endemismo do deserto do Namibe (SW de África). Distribui-se desde o Rio Nicolau, em Angola, até ao rio Kuiseb, na Namíbia, nunca se distanciando muito da costa (Kers, 1967). Pouco mais de cem anos após a descrição original, as populações namibianas foram segregadas numa subespécie autónoma - subsp. namibiana com base na morfologia dos cones masculinos, quedando as populações angolanas na subespécie tipo (subsp. mirabilis) (Leuenberger, 2001). Esta taxonomia, porém, não é consensual (Jacobson, Jacobson, van Jaarsveld \& Jacobson, 2014).

Figura 1. Welwitschia mirabilis subsp. mirabilis (Welwitschiaceae) no Rio dos Flamingos deserto do Namibe (Angola).

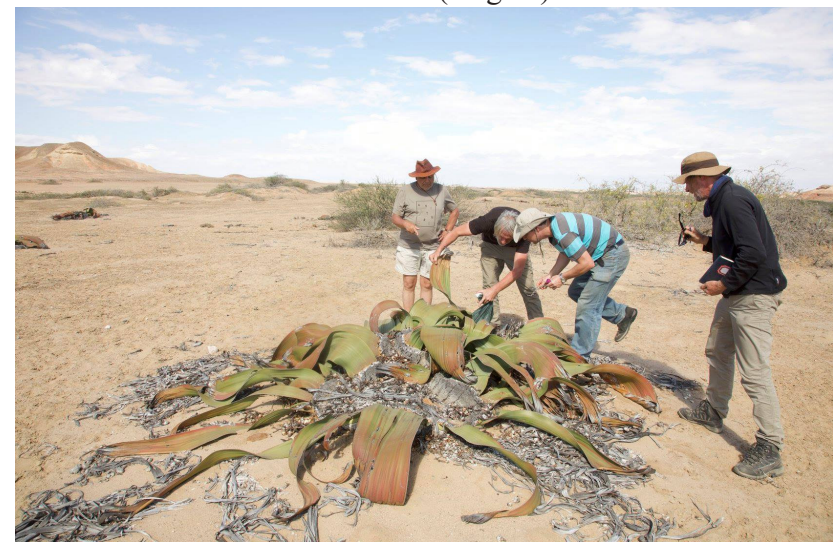

A W. mirabilis é uma planta fora do comum dos pontos de vista morfológico, fisiológico, evolutivo e ecológico. O sistema radicular raiz é longo e profundante, como é usual nas plantas perenes do deserto. O caule é constituído por um eixo lenhoso curto e espesso, não ramificado, distalmente alargado num disco (coroa) que pode ultrapassar os $50 \mathrm{~cm}$ de diâmetro. Geralmente produz dois, eventualmente três pares de folhas (von Willert, 1993). O primeiro par - os cotilédones 
- é rapidamente substituído por duas folhas opostas longas (até $4 \mathrm{~m}$ ) persistentes durante toda a vida da planta (von Willert, 1985). A produção de novas folhas cessa logo em seguida ficando a planta truncada na extremidade distal. As duas folhas alongam-se continuamente pela base a partir de meristemas intercalares foliares situados na interface da folha com a coroa. A destruição dos meristemas intercalares pela herbivoria comprometem irremediavelmente a sobrevivência da planta (Bruce Bennett, comunicação oral). A W. mirabilis é uma planta dioica coexistem indivíduos masculinos e femininos (Bornman, Botha \& Nash, 1973) - característica que, não sendo rara, é minoritária entre as plantas-com-semente. Anualmente, na margem da coroa, por baixo ou por cima das folhas, emergem estruturas reprodutivas - cones masculinos ou femininos. A polinização é realizada por insetos (entomófila). As sementes são aladas (têm duas asas) e dispersas pelo vento. Superficialmente, a $W$. mirabilis assemelha-se a uma planta recém-germinada, de enorme tamanho, ou com a copa truncada. Esta estranha fisionomia conferiu-lhe o epiteto de "a planta mais feia do Mundo" (Bustard, 1990). O crescimento é muito lento e a longevidade notável. Datações por carbono-14 indicam que plantas relativamente pequenas têm entre 500-600 anos. Para as plantas de maior dimensão estimou-se 2000 a 3000 anos, embora estes valores careçam de confirmação (Henschel \& Seely, 2000).

As estratégias usadas pela $W$. mirabilis para sobreviver à escassez de água no solo são distintas das outras plantas do deserto, mas ainda largamente desconhecidas. As folhas pequenas (microfilia) ou gordas (crassifolia), a caducifolia de estação seca, e a terofitia (ciclo de vida anual) são quatro das adaptações mais frequentes nas plantas dos desertos e semidesertos tropicais (vd. Breckle, 2002). A W. mirabilis escapa a este padrão, facto que the confere um papel ecológico muito relevante para algumas espécies de animais, porque, além da biomassa verde que lhes serve alimento, as grandes folhas fornecem refúgio e sombra, mantendo a temperatura do solo mais de $20^{\circ} \mathrm{C}$ abaixo da temperatura dos solos adjacentes (Marsh, 1990). As perdas de água por transpiração são relativamente elevadas em condições de campo, cerca de 1L/dia nas plantas de tamanho médio (Eller, von Willert, Brinkmann \& Baasch, 1983). Por alguma razão as plantas cultivadas, ao invés, por exemplo, das Cactaceae, exigem regas copiosas. A $W$. mirabilis realiza um tipo de fotossíntese eficaz a reduzir perdas de água - o chamado Metabolismo Ácido das Crassuláceas (CAM). No entanto, por razões que se desconhecem, a quantidade assimilada de $\mathrm{CO}_{2}$ por esta via é apenas cerca de $4 \%$, um valor surpreendentemente baixo para uma planta de ambientes tão extremos (von Willert, Armbrüster, Drees \& Zaborowski, 2005). Em períodos de seca extrema, as plantas fecham os estomas reduzindo as perdas de água; o consequente deficit (fome) 
de $\mathrm{CO}_{2}$ só parcialmente pode ser compensado com reservas de carbono acumuladas nas partes antigas das folhas (Eller, von Willert, Brinkmann \& Baasch, 1983). As adaptações fisiológicas da W. mirabilis à falta de água são, aparentemente, limitadas, e uma vez que não exibe dormência, a sobrevivência dos indivíduos depende de um acesso praticamente contínuo à água (Henschel \& Seely, 2000). A bibliografia refere, e a nossa experiência de campo confirma, que esta espécie ocupa microssítios hidricamente compensados, beneficiados pela escorrência e concentração de áreas imediatamente vizinhas (e.g., fendas de rochas, cabeceiras de linhas de água temporárias e a base dos inselbergs), ou por toalhas freáticas profundas (e.g., leitos secos de rios do deserto) (vd. Kers, 1967).

Figura 2. Filograma de máxima verossimilhança, baseado em 106 genes de cópia única, suportando uma hipótese das relações evolutivas entre os grandes grupos de plantas-com-semente. Adaptado de Li et al. (2017).

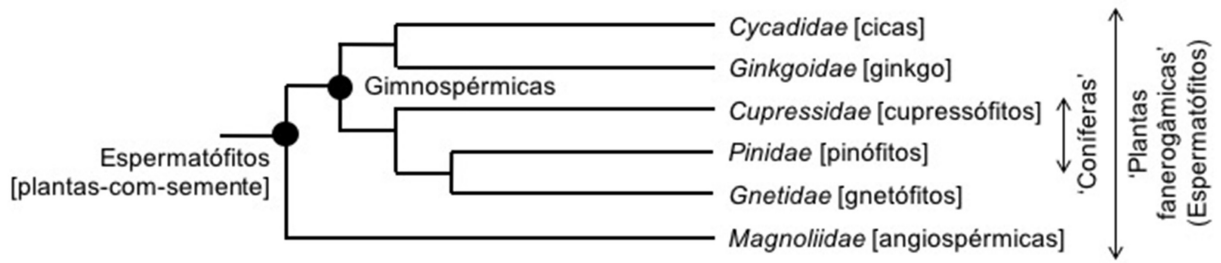

Das inúmeras linhagens de plantas-com-semente que povoaram o planeta entre o Devónico e o final do Mesozoico sobreviveram até ao presente apenas seis (relações evolutivas resumidas na Figura 1). As angiospérmicas (plantas-comflor), de todas a mais recente, é dominante na grande maioria dos ecossistemas terrestres, com aproximadamente 352.000 espécies conhecidas, mais $10-20 \%$ por descrever (Joppa, Roberts, \& Pimm, 2011). No âmbito das gimnospérmicas plantas-com-semente sem flor - reconhecem-se cinco grandes linhagens, que em conjunto perfazem apenas cerca de 1.000 espécies (Christenhusz et al., 2011). As gimnospérmicas incluem as cicas, os ginkgófitos - uma linhagem monoespecífica representada pelo ginkgo (Ginkgo biloba) -, os pinófitos (pinheiros, abetos e afins), os cupressófitos (ciprestes e outras espécies), e os gnetófitos, com apenas 3 géneros, Gnetum, Ephedra e Welwitschia, e cerca de 30 espécies. Os pinófitos e os cupressófitos constituem as coníferas, um grupo provavelmente parafilético (não inclui todos os descendentes de um ancestral comum).

Durante cerca de 100 anos, os gnetófitos foram considerados o grupo irmão das angiospérmicas, ou mesmo o seu ancestral mais direto. Esta proximidade foi deduzida a partir do elevado número de características partilhadas com as plantas-com-flor; e.g., a presença de células especiais (elementos de vaso) no tecido 
(xilema) que transporta a seiva bruta, polinização entomófila, estruturas reprodutivas (cones) bissexuais, primórdios seminais envolvidos por estruturas similares ao carpelo das angiospérmicas e o facto de em alguns Gnetum ocorrer um esboço de dupla fecundação (Carmichael \& Friedman, 1995). No entanto, desde a década de 90, com o advento da biologia molecular e da sequenciação de ADN, têm vindo a acumular-se evidências de que os gnetófitos são, na realidade, um grupo irmão dos pinófitos, evolutivamente distante das angiospérmicas (Doyle, 1998; Goremykin et al., 1996) (Figura 2). A sua relação com as coníferas não está encerrada, mas a hipótese dos gnetófitos serem uma linhagem irmã das angiospérmicas parece excluída (Wang \& Ran, 2014). As similaridades morfológicas dos gnetófitos com as angiospérmicas devem ser reinterpretadas como um fenómeno de convergência evolutiva (Donoghue \& Doyle, 2000), um processo evolutivo que gera morfologias semelhantes em linhagens sem relação evolutiva direta, em consequência de pressões seletivas similares. Ao contrário dos outros dois géneros de gnetófitas (Gnetum e Ephedra), o género Welwitschia tem atualmente uma distribuição geográfica muito restrita e compreende uma única espécie: $W$. mirabilis. Um abundante e diverso registo fóssil que recua ao Cretácico Inferior indicia que a linhagem da Welwitschia outrora se expandia pela África, América do Sul, China, Ásia Central, Europa e América do Norte (Friis, Pedersen \& Crane, 2014; Hou, 2014). A $W$. mirabilis é uma relíquia do passado, um fóssil vivo.

O deserto do Namibe desenvolve-se ao longo do litoral angolano, a sul da cidade do Namibe, e prolonga-se até à Africa do Sul paralelo ao litoral namibiano. O tramo final do rio Cunene disseca o deserto no sentido Este-Oeste - constitui uma fronteira natural entre a Namíbia e Angola, e circunscreve o que outrora se designou por deserto de Moçâmedes (sector angolano do atual deserto do Namibe). Trata-se de uma área com uma geomorfologia de grande complexidade comportando um extenso sistema dunar constituído por dunas de grande mobilidade com dezenas de metros de altura, que tem como fronteira em Angola o rio Curoca. Este importante curso de água trava o movimento para norte e para o interior das areias transportadas pelos ventos dominantes de oeste e sudoeste. Para além dos extensos campos de dunas, no deserto do Namibe observam-se alinhamentos de inselbergs (alguns de elevada dimensão) de grande originalidade pelas suas formas exóticas de erosão, diferenciados sob um clima quente e húmido, antes da aridificação iniciada no Miocénico Inferior (Amaral, 1973). Os inselbergs são o habitat de uma diversa e original flora arbustiva e arbórea (e.g., gen. Commiphora, Euphorbia, Acacia, Boscia, Combretum, Moringa e Sesamothamnus). Nas regiões desérticas com precipitação média anual inferior a 100 $\mathrm{mm}$, é conhecida, e muito estudada, a associação entre os afloramentos rochosos 
e a dominância de arbustos e árvores frequentemente nanificados, por oposição às formações de gramíneas características dos solos de textura arenosa (Esler, Milton \& Dean, 2006). As superfícies de rocha viva concentram a água da chuva em fendas, em quantidade suficiente para sustentar plantas de grande biomassa, de outro modo incapazes de prosperar com tão baixas precipitações.

$\mathrm{Na}$ área de estudo, i.e., na área de distribuição da W. mirabilis em Angola, reconhecem-se, então, dois grandes espaços do ponto de vista geomorfológico e ecológico: (i) afloramentos de rochas do Maciço Antigo, maioritariamente pré-câmbricas (granitos, gnaisses, xistos, grauvaques entre as mais abundantes), entre os quais sobressaem os inselbergs; (ii) as dunas móveis que cobrem o extremo sudoeste do Parque do Iona, desde o vale do Curoca até ao mar (Amaral, 1977, 1982). Ainda assim, neste segundo conjunto, é possível observar alguns afloramentos de granito róseo da superfície fundamental nas áreas de deflação, onde o vento arrastou as areias (e.g., ao longo do percurso pela praia desde a Foz do Cunene até Tômbua), e em alguns nos espaços interdunares muito profundos. Por seu turno, os relevos residuais, designados por inselbergs (com diferentes composições geológicas, embora na sua maioria sejam formados por amontoados de blocos graníticos), são separados por superfícies de aplanamento cobertas por sedimentos (piedmont plain), nas quais se distingue um pediment (mais próximo do inselberg) e leques aluviais (planícies aluviais). As variações granulométricas nas superfícies de aplanamento são impressionantes - vão desde uma dominância quase total da matriz arenosa, sobretudo próximo dos inselbergs na lomba do pediment, às áreas de deserto pedregoso (integrados dos leques aluviais) com abundante material grosseiro (cascalho) numa matriz arenosa. A $W$. mirabilis habita as regiões onde afloram as rochas do Maciço Antigo; a distribuição dos sedimentos tem, como se verá, um grande impacto na distribuição da espécie.

Do ponto de vista climático, na área estudada as isoietas estão compreendidas entre os 20 e os 100 mm (média 1914-1969) (Daveau, 1972; Dinis, 1991) sendo que a faixa litoral entre Tômbua e a Foz do Cunene não ultrapassa os $20 \mathrm{~mm}$ anuais (Daveau, 1972) (Figura 3). As temperaturas mais elevadas registam-se durante o período das chuvas (janeiro a abril). Os valores baixos de precipitação estão relacionados com a estabilização das massas de ar oceânicas arrefecidas pela baixa temperatura das águas marítimas da corrente de Benguela o que leva, contudo, à enorme frequência de nevoeiros que este deserto litoral regista. Estes nevoeiros penetram, em determinadas situações, cerca de $100 \mathrm{~km}$ para o interior (Amaral, 1973). É conhecida, e tem sido estudada, a importância destes nevoeiros no fornecimento de água e na sobrevivência dos vegetais do deserto do Namibe (Hachfeld \& Jurgens, 2000). Devido à influência da corrente fria de Benguela, os valores da temperatura da água do mar oscilam entre $16^{\circ} \mathrm{C}$ e apenas em fevereiro, março e 
abril podem superar os $20^{\circ} \mathrm{C}$, chegando a atingir os $25^{\circ} \mathrm{C}$ (Silveira, 1969). Desta forma, mesmo durante o período quente e chuvoso, as temperaturas do ar nunca são muito elevadas tendo em conta a latitude do território estudado (Amaral, 1973) - a temperatura média anual situa-se entre os 19 e $23^{\circ} \mathrm{C}$ na área de estudo (Dinis, 1991). Quanto à classificação de Köppen, a área de estudo apresenta um clima de tipo BWh-clima árido, desértico quente (Griffiths, 1972; Schulze, 1947).

Do ponto de vista biogeográfico, o deserto do Namibe começou a individualizar-se há cerca de 17,5 milhões de anos, quando o território do atual Sáara estava ainda colonizado por florestas tropicais (Senut, Pickford \& Ségalen, 2009). A aridez do deserto do Namibe permaneceu genericamente estável quando comparada com o Sáara - desde a sua formação há 7,5 milhões de anos, o Sáara atravessou cerca de 230 períodos de maior precipitação (os chamados períodos verdes do Sáara) (Grant et al., 2017; Larrasoaña et al. 2013; Skonieczny et al., 2015). A extensão do deserto do Namibe variou ao longo do tempo. No início do Miocénico estendia-se até à bacia do Congo, próximo do Equador. Em épocas geológicas mais recentes (Pleistocénico), cresceu em latitude e para o interior nos períodos glaciais (de maior secura) e contraindo-se nos interglacial. Estudos recentes revelam um aumento da precipitação invernal (período frio) - e a convergência num clima de tipo mediterrânico - durante os períodos glaciais, em consequência de uma subida para norte da frente polar (Dupont, 2006). Estas inversões no ritmo de precipitação anual tiveram certamente uma influência significativa na flora e vegetação atuais - e.g., especiação de plantas bulbosas e crassifólias -, as quais não são ainda conhecidas na sua totalidade. De qualquer forma é marcante a estabilidade da aridez do deserto do Namibe desde a sua formação até à atualidade, um facto chave para explicar o elevado número de endemismos presente neste imenso território.

Figura 3. Distribuição das precipitações na área estudada, segundo Daveau (1972), e localização

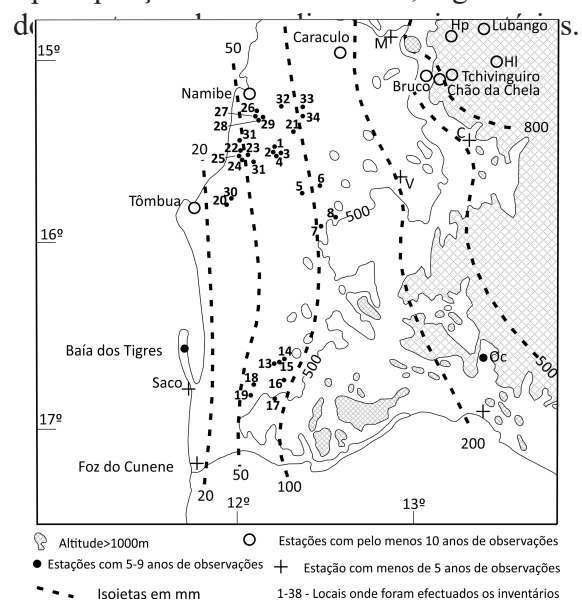


O deserto do Namibe não é uma entidade biogeográfica homogénea. Alguns autores segmentam o deserto do Namibe em função da distribuição da precipitação e do efeito que esta tem na estrutura da vegetação - a época das chuvas desloca-se para a estação fria de norte para sul, ao mesmo tempo, por exemplo, que as plantas crassas ganham importância. Outros valorizam o substrato - e.g., áreas com substratos arenosos móveis vs. territórios rochosos e/ou detríticos não mobilizáveis pelo vento. A WWF (WWF Ecoregions) distribui a área de estudo por duas unidades fitogeográficas: AT1310-Kaokoveld Desert e AT1316 - Namibian Savanna Woodlands. Outra classificação fitogeográfica recente, da autoria de Linder et al. (2012), baseada em aves, mamíferos, anfíbios e cobras (vertebrados) e plantas, propõe uma sub-região Sudoeste Angolana, no âmbito da vasta Região Sul Africana. White (1983), tendo como base apenas a flora e vegetação, considera um Centro Regional de Endemismos Karoo-Namibe, repartido por duas subunidades: Deserto do Namibe e Vegetação arbustiva baixa Karoo-Namibe. De acordo com o mesmo autor, a área de estudo está maioritariamente incluída na primeira das subunidades (predominantemente litoral e arenosa com dunas de grande dimensão, alguns inselbergs e vales de enchimento detrítico). Na segunda subunidade, mais interior, predominam os inselbergs e os aplanamentos [ou plainos como the chama Amaral (1973)] cobertos por sedimentos arenosos e/ou pedregosos (piedmont). Por último, vale a pena referir que Gossweiler e Mendonça (1939), de modo similar, consideram dois territórios fitogeográficos litorais na porção angolana do deserto do Namibe: 1. Deserto de Seca e Litorideserta; 2. Mobilideserta (associada à ocorrência de dunas móveis e coberturas arenosas).

\section{Objectivos}

A W.mirabilis é a planta símbolo de Angola, e um magneto para os botânicos -e faz todo o sentido que o seja. São raras as espécies de plantas com uma bibliografia tão vasta e diversificada de ecofisiologia e de evolução. Todavia, as comunidades vegetais de $W$. mirabilis são pouco conhecidas. Publicações clássicas como as Cartas Fitogeográficas de Gossweiler (1939) e de Grandvaux Barbosa (1970) desenvolvem escassamente o tema. Na sequência do trabalho recente e pioneiro de Cardoso (2015) realizou-se em abril e maio de 2018 uma expedição geobotânica internacional ao Deserto do Namibe/Foz do Cunene, organizada conjuntamente pela Universidade José Eduardo dos Santos (Huambo), Universidade de Lisboa, Associação Portuguesa de Ciência da Vegetação (PHYTOS) e Société Française de Phytosociologie (SFP). Um dos objetivos desta expedição consistiu no estudo da vegetação de $W$. mirabilis de acordo com os princípios e métodos 
da fitossociologia clássica (sigmatista), cujos resultados preliminares agora se divulgam.

\section{Material e métodos}

No presente estudo da vegetação dominada por $W$ mirabilis no Sudoeste de Angola adotaram-se os métodos e os conceitos da escola de fitossociologia de Zurique-Montpellier e da sua mais recente extensão - a fitossociologia de paisagem ou fitossociologia dinâmico-catenal. Uma descrição pormenorizada, total ou parcial, da Fitossociologia Integrada (Fitossociologia Clássica + Fitossociologia de Paisagem) está publicada, por exemplo, em Mueller-Dombois e Ellenberg, (1974), Géhu e Rivas-Martínez (1981) e Géhu (1987). O trabalho de Capelo (2003) é a melhor introdução escrita em língua portuguesa. Na metodologia fitossociológica distinguem-se duas fases fundamentais: a fase analítica e a fase sintética. A fase analítica consistiu na procura e inventariação de áreas com um tipo de vegetação espacialmente recorrente homogéneo dos pontos de vista fisionómico, florístico e ecológico, no presente caso, com a presença de W. mirabilis. Após a selecção da área de amostragem, as espécies presentes foram rigorosamente inventariadas e avaliado o seu grau de cobertura (escala de Braun-Blanquet). Simultaneamente, foram tomadas as coordenadas geográficas e quantificados alguns fatores ecológicos a priori considerados relevantes (e.g., altitude, exposição, declive, litologia). Durante os trabalhos de campo efetuaram-se 19 inventários de comunidades de W. mirabilis, entre abril e maio de 2018. A estes adicionaram-se os 15 inventários disponíveis na dissertação de Cardoso (2015), perfazendo um total de 34 inventários (Figura 4). A identificação das plantas realizou-se, em grande parte, no herbário LISC, sediado no Instituto de Investigação Científica Tropical (Lisboa). A fase sintética, resumidamente, consistiu na organização dos inventários em tabelas de Excel em função da sua frequência e do seu significado ecológico, e na sua posterior análise e classificação. A etapa sintética pode, com vantagem, ser assistida por algoritmos computacionais. Para este trabalho efetuou-se uma análise de correspondências retificada (DCA) no programa CANOCO 5.0 (Ter Braak \& Šmilauer, 2012). Como a utilização direta da escala alfanumérica de Braun-Blanquet em análises numéricas não é possível, foi necessário a sua transformação segundo a proposta de van der Maarel (2007). O método fitossociológico tem como produto final um sistema de classificação geralmente formalizado num sistema sintaxonómico que tem como unidade elementar a associação. Nos resultados, adiante explicitados, foram omitidas as tabelas fitossociológicas. Uma discussão detalhada da sintaxonomia das comunidades de W. mirabilis fica relegada para uma publicação especializada na área da ciência da vegetação. 


\section{Resultados e Discussão}

A análise de correspondências dos 34 inventários segrega quatro grupos identificáveis com outras tantas associações fitossociológicas, que se descrevem em seguida (Figura 4).

\section{A. Welwitschietum mirabilis Cardoso e J.C. Costa inéd. (figura 5)}

Comunidade descrita por Cardoso (2015) própria dos piedmont plain das áreas mais a norte do Deserto do Namibe angolano. Em ambientes mais extremos - de baixa precipitação ou em depósitos arenosos espessos - a $W$. mirabilis é a única planta perene dispondo-se em mosaico com comunidades paucispecíficas de plantas anuais dominadas por Zygophyllum simplex (figura 5). Estas são as áreas mais secas das superfícies sedimentares que cobrem as depressões entre os inselbergs preenchidas por leques aluviais, topograficamente sempre em posição mais elevada (interflúvios) do que as comunidades de $W$. mirabilis e $A$. recifiens que colonizam os valeiros de fundo plano definidos pelos cursos de água efémeros. Os sedimentos são, aparentemente, pouco espessos de modo a permitir o enraizamento da $W$. mirabilis nas plataformas rochosas subjacentes da superfície fundamental.

Figura 4. Análise de correspondências retificada (DCA - Detrended correspondence analysis) obtida com o programa CANOCO V.5.0 (Ter Braak \& Šmilauer 2012) dos inventários de comunidades de W. mirabilis realizados no deserto do Namibe (Angola). A - Welwitschietum mirabilis Cardoso e J.C. Costa inéd; B -Welwitschio mirabilis-Acacietum reficiens Cardoso e J.C. Costa inéd, (B1 facies com Boscia pestalozziana); C - Comunidade de W. mirabilis dominada por espécies do género Commiphora spp.; D - Comunidade de W. mirabilis dominada por Stipagrostis hochstetteriana var. secalina. (os inventários de 1-34 estão localizados na figura 3)

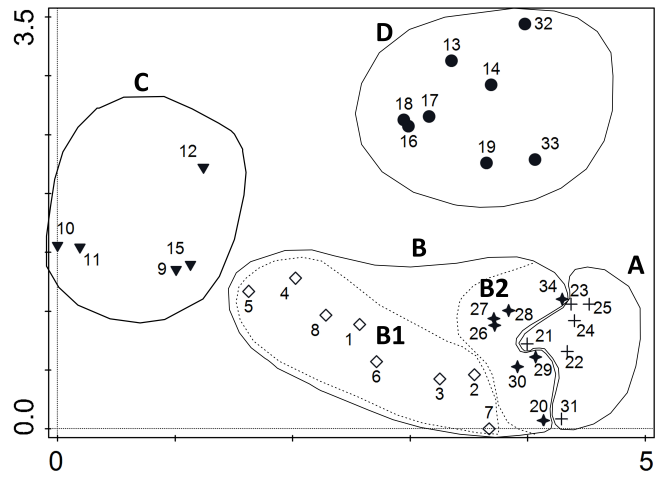

Quadro 1. Resumo dos resultados estatísticos da DCA (Análise de correspondências retificada Detrended correspondence analysis) Program Canoco 5.0 for windows CANOCO 5.0 software (Ter Braak \& Šmilauer, 2012).

\begin{tabular}{|l|c|c|c|}
\hline & Eixo 1 & Eixo 2 & Eixo 3 \\
\hline Valores próprios (eigenvalues) & 0,7698 & 0,5010 & 0,3377 \\
\hline Variação explicada (cumulativa) & 11,80 & 19,48 & 24,66 \\
\hline Comprimento do gradiente & 4,52 & 3,44 & 3,15 \\
\hline
\end{tabular}


Figura 5. Welwitschietum mirabilis Cardoso e J.C. Costa inéd. com Zygophyllum simplex numa superfície plana de topo (interflúvio) com material grosseiro. Ao fundo observa-se um alinhamento de espinheiras (A. recifiens entre outras espécies, num vale de curso de água efémero) que constituem uma segunda associação própria dos cursos de água efémeros (Welwitschio mirabilis-Acacietum reficiens Cardoso e J.C. Costa inéd.). Omahua (Parque Nacional do Iona).

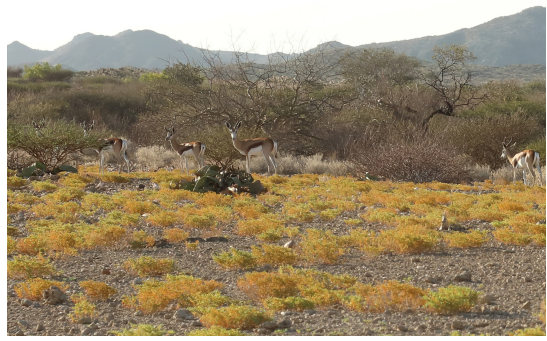

B. Welwitschio mirabilis-Acacietum reficiens Cardoso e J.C. Costa inéd.

\section{(figuras 6 e 7)}

O número de espécies perenes aumenta nos espaços mais favoráveis, principalmente nos cursos de água efémeros que recebem águas de escorrimento superficial provenientes de superfícies rochosas extensas, cobertas por sedimentos arenosos pouco profundos e/ou onde a toalha freática se encontra próxima da superfície. Trata-se de cursos de água que apenas têm escorrência quando chove, mas devido ao regime torrencial apresentam uma grande heterometria dos sedimentos (areias de diferentes calibres a calhaus de diferentes dimensões (Amaral, 1982) A $A$. reficiens é particularmente frequente nestas condições formando mesmo alinhamentos que serpenteiam a paisagem associadas a estes cursos de água efémeros. Próximo do litoral entra a Boscia pestalozziana. Nos fundos de vale de maior humidade, supomos com toalhas freáticas acessíveis, a W. mirabilis é acompanhada por uma outra lenhosa, a Salvadora persica que corresponderá um fácies um pouco mais húmido da comunidade de cursos de água efémeros de W. mirabilis, A. reficiens e B. pestalozziana (figura 4 facies $\mathrm{B} 1$ ).

Figura 6. Alinhamento de espinheiras (A. reficiens) com W. mirabilis (Welwitschio mirabilis-Acacietum reficiens Cardoso e J.C. Costa inéd.) nos cursos de água efémeros das planícies sedimentares resultantes dos leques aluviais que transportam os sedimentos a partir dos inselbergs (ao fundo na imagem). Espinheira (Parque Nacional do Iona).

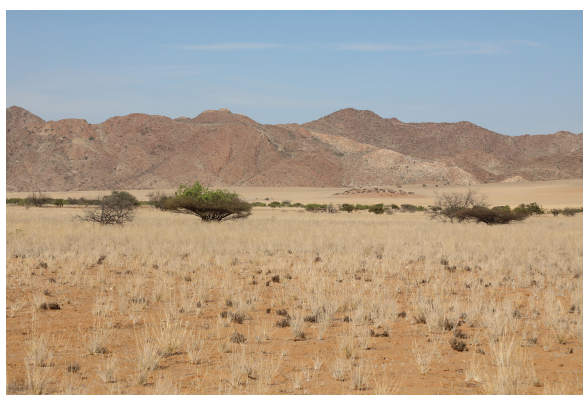


Figura 7. A. recifiens, W. mirabilis com B. pestalozziana num fundo de curso de água efémero (Welwitschio mirabilis-Acacietum reficiens Cardoso e J.C. Costa inéd.). Rio dos Flamingos (Tômbua).

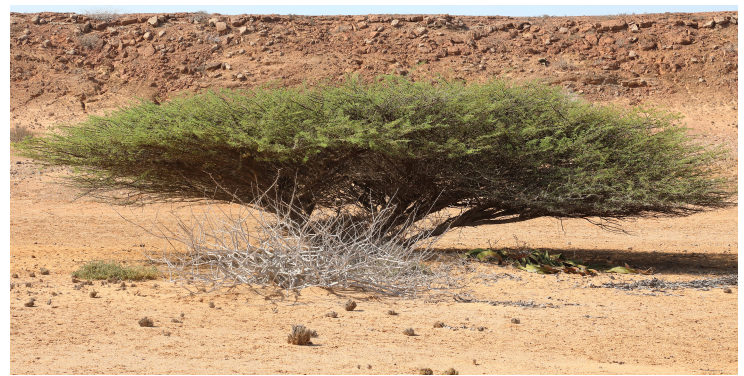

\section{Comunidade de Commiphora sp.pl. e W. mirabilis (figura 8)}

Trata-se de uma comunidade nanofanerofítica, própria de fendas rochosas mais ou menos preenchidas com areias, localizadas no sopé de inselbergs xistosos ou grauváquicos. Esta comunidade é de todas as formações vegetais com $W$. mirabilis a mais diversa em espécies perenes, entre as quais se destacam várias Commiphora; e.g., C. saxatilis, $C$. wildii e $C$. virgata (figura 6) e também algumas suculentas como a Euphorbia virosa subsp. virosa que frequentemente acompanha estas comunidades.

Figura 8A e B. Comunidade de Commiphora sp.pl. e W. mirabilis. Parque Nacional do Iona entre o Curoca e Espinheira em inselbergs de xistos e/ou grauvaques précambricos.
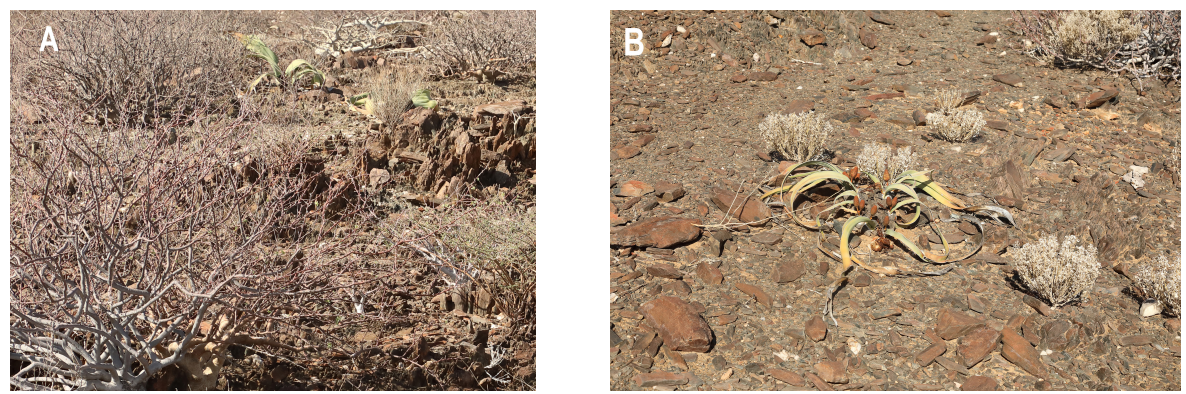

Figura 9. Savana nanofanerofítico de Stipagrostis hochstetteriana var. secalina e W. mirabilis no Parque Nacional do Iona (Espinheira). Frequentemente, a matriz arenosa tem origem eólica sendo transportada pelos ventos dominantes a partir do litoral. Espinheira (Parque do Iona).

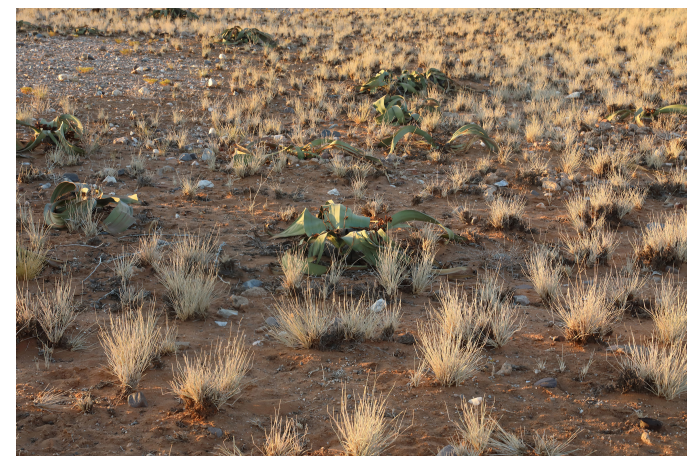




\section{Savana nanofanerofítica de Stipagrostis hochstetteriana var. secalina e W. mirabilis (figura 9)}

Savana nanofanerofítica com uma elevada cobertura de S. hochstetteriana var. secalina. Tem por habitat zonas de piedmont plain cobertas por sedimentos arenosos, por vezes enriquecidos com frações mais grosseiras (cascalho e calhaus). A espessura dos sedimentos é suficientemente delgada para permitir o enraizamento da $W$. mirabilis nas plataformas rochosas subjacentes da superfície fundamental. Ainda assim, a $W$. mirabilis, raramente é acompanhada por outras espécies lenhosas. Esta comunidade tem grande expressão no Parque Nacional do Iona sendo substituída, a norte, em habitats similares mas mais litorais, pela suprarreferida Welwitschietum mirabilis.

\section{Conclusão}

O estudo das comunidades vegetais dominadas por $W$. mirabilis realizado no âmbito da Expedição Geobotânica realizada ao SW de Angola revelou a existência de comunidades fitossociológicas que, apesar de aqui fazermos a sua descrição e diferenciação florística, carecem de estudos posteriores de caracter laboratorial para descortinar detalhadamente as principais variáveis ambientais que intervêm na sua individualização florística e estrutural. A análise dos inventários fitossociológicos de forma manual e com recuso a técnicas estatísticas multivariadas resultou numa separação em 4 comunidades claramente separadas do ponto de vista florístico e hidrogeomorfológico. Uma comunidade claramente edafo-higrófila associada a linhas de água temporárias frequentemente com uma toalha freática próxima da superfície (Welwitschio mirabilis-Acacietum reficiens), uma segunda associada às áreas planas (interflúvios) das planícies de enchimento, entre os cursos de água temporários (Welwitschietum mirabilis), outra associada a plataformas arenosas (savana nanofanerofítica de Stipagrostis hochstetteriana var. secalina e $W$. mirabilis), e uma última característica dos sectores basais dos inselbergs de xistos e grauvaques presente apenas nos territórios para sul de Oumahua Lodge até ao rio Cunene (Comunidade de Commiphora sp.pl. e $W$. mirabilis).

\section{Referências}

Amaral, I. (1973). Formas de "inselberge" (ou montes-ilhas e de meteorização superficial e profunda em rochas graníticas do Deserto de Moçâmedes (Angola) na margem direita do rio Curoca. Garcia Da Orta, Serie Geografia, 1(1), 1-34.

Amaral, I. (1977). Paisagens morfolóficas do deserto de Moçâmedes (Angola), entre os rios Curoca e Cunene (1 $1^{\text {a }}$ parte). Garcia Da Orta, Serie Geografia, 4(1,2), 1-28. 
Amaral, I. (1982). Paisagens morfolóficas do deserto de Moçâmedes (Angola), entre os rios Curoca e Cunene ( $2^{\mathrm{a}}$ parte - Processos eólicos). Garcia Da Orta, Serie Geografia, 7(1,2 2), 1-34.

Bornman, C. H., Botha, C. E. J., \& Nash, L. J. (1973). Welwitschia mirabilis: observations on movement of water and assimilates under föhn and fog conditions. Madoqua, 3, 63-68.

Breckle, S. (2002). Walter's Vegetation of the Earth: the Ecological Systems of the Geo-biosphere (4th, compl ed.). Berlin; New York: Springer.

Bustard, L. (1990). The ugliest plant in the world: the story of Welwitschia mirabilis. Kew Magazine, 7, 85-90.

Capelo, J. (2003). Conceitos e métodos da Fitossociologia: Formulação contemporânea e métodos numéricos de análise da vegetação. Oeiras: Estação Florestal Nacional, Sociedade Portuguesa de Ciências Florestais.

Cardoso, J. F. (2015). Estudo geobotânico do sudoeste angolano desde a Tundavala ao Tombua. Tese para a obtenção do grau de Doutor em Engenharia Agronómica. Instituto Superior de Agronomia, Universidade de Lisboa.

Carmichael, J. S., \& Friedman, W. E. (1995). Double Fertilization in Gnetum gnemon: The Relationship between the Cell Cycle and Sexual Reproduction. Plant Cell, 7(12), 1975-1988. https:// doi.org/10.1105/tpc.7.12.1975

Christenhusz, M. J. M., Reveal, J. L., Farjon, A., Gardner, M. F., Mill, R. R., \& Chase, M. W. (2011). A new classification and linear sequence of extant gymnosperms. Phytotaxa, 19, $55-70$.

Daveau, S. (1972). Contribuition à l'étude climatique du désert côtier d'Angola. In Études de géographie tropicale ofertes à Pierre Gourou (pp. 263-278). Paris - La Haye: Mouton.

Dinis, A. C. (1991). Angola Meio Físico e Potencialidades Agrárias. Lisboa: Instituto para a Coperação Económica.

Donoghue, M. J., \& Doyle, J. A. (2000). Seed plant phylogeny: demise of the anthophyte hypothesis? Current Biology, 10(3), R106-R109. https://doi.org/10.1016/S0960-9822(00)00304-3

Doyle, J. A. (1998). Phylogeny of Vascular Plants. Annual Review of Ecology and Systematics, 29(1), 567-599. https://doi.org/doi:10.1146/annurev.ecolsys.29.1.567

Dupont, L. M. (2006). Late Pliocene vegetation and climate in Namibia (southern Africa) derived from palynology of ODP Site 1082. Geochemistry, Geophysics, Geosystems, 7(5). https://doi. org/10.1029/2005GC001208

Eller, B. M., von Willert, D. J., Brinkmann, E., \& Baasch, R. (1983). Ecophysiological studies on Welwitschia mirabilis in the Namib Desert. South African Journal of Botany, 2, 209-223.

Esler, K. J., Milton, S., \& Dean, W. R. J. (2006). Karoo veld: Ecology and management. Pretoria: Briza Press.

Friis, E. M., Pedersen, K. R., \& Crane, P. R. (2014). Welwitschioid diversity in the Early 
Cretaceous: Evidence from fossil seeds with pollen from Portugal and eastern North America. Grana, 53(3), 175-196. https://doi.org/10.1080/00173134.2014.915980

Géhu J.-M. (1987). Des complexes de groupements végétaux à la phytosociologie paysagère contemporaine. Inf. Bot. Ital., 18, 1-2-3, 53-83.

Géhu, J.-M., \& Rivas-Martínez, S. (1981). Notions Fondamentales de Phytosociologie. Syntaxonomie. In H. Dierschke (Ed.), Berichte Internationalen Symposien der Internationalen Vereinigung für Vegetationskunde. Vaduz: J. Cramer.

Goremykin, V., Bobrova, V., Pahnke, J., Troitsky, A., Antonov, A., \& Martin, W. (1996). Noncoding sequences from the slowly evolving chloroplast inverted repeat in addition to rbcL data do not support gnetalean affinities of angiosperms. Molecular Biology and Evolution, 13(2), 383-396. https://doi.org/10.1093/oxfordjournals.molbev.a025597

Gossweiler, J. (1939). Carta fitogeográfica de Angola / J. Gossweiler; colab. F. A. Mendonça. - : Governo Geral De Angola, 1939. - 236 p. Luanda: Governo Geral de Angola.

Grandvaux Barbosa, L. A. (1970). Carta fitogeográfica de Angola. Luanda: Instituto de Investigação Científica de Angola.

Grant, K. M., Rohling, E. J., Westerhold, T., Zabel, M., Heslop, D., Konijnendijk, T., \& Lourens, L. (2017). A 3 million year index for North African humidity/aridity and the implication of potential pan-African Humid periods. Quaternary Science Reviews, 171, 100-118. https://doi. org/10.1016/j.quascirev.2017.07.005

Griffiths, J. F. (ed.) (1972). Climates of Africa. World Survey of Climatology, Volume 10. New York: Elsevier.

Hachfeld, B., \& Jurgens, N. (2000). Climate patterns and their impact on the vegetation in a fog driven desert: The Central Namib Desert in Namibia. Phytocoenologia, 30(3-4), 567-589. https:// doi.org/10.1127/phyto/30/2000/567

Henschel, J. R., \& Seely, M. K. (2000). Long-term growth patterns of Welwitschia mirabilis, a long-lived plant of the Namib Desert (including a bibliography). In Plant Ecology (Vol. 150, pp. 7-26). https://doi.org/10.1023/A:1026512608982

Hooker, J. D. (1862). On Welwitschia mirabilis. Gard. Chron., 1862, 71.

Hou, C. (2014). Proteomics and phylogenetics of the Gnetales. Stockholm University.

Jacobson, N., Jacobson, P., Van Jaarsveld, E., \& Jacobson, K. (2014). Field evidence from Namibia does not support the designation of Angolan and Namibian subspecies of Welwitschia mirabilis Hook. Transactions of the Royal Society of South Africa, 69(3), 179-186. https://doi.org/ 10.1080/0035919X.2014.950187

Joppa, L. N., Roberts, D. L., \& Pimm, S. L. (2011). How many species of flowering plants are there? Proceedings of the Royal Society B: Biological Sciences, 278(1705), 554-559. https://doi. org/10.1098/rspb.2010.1004

Kers, L. E. (1967). The distribution of Welwitschia mirabilis Hook.f. Svensk Botanisk Tidskrift, $61,97-125$. 
Larrasoaña, J.C., Robert.s A.P. \& Rohling, E.J. (2013) Dynamics of Green Sahara Periods and Their Role in Hominin Evolution. PLoS ONE 8(10): e76514. https://doi.org/10.1371/journal. pone. 0076514

Leuenberger, B. E. (2001). Welwitschia mirabilis (Welwitschiaceae), male cone characters and a new subspecies. Willdenowia, 31, 357-381.

Li, Z., De La Torre, A. R., Sterck, L., Cánovas, F. M., Avila, C., Merino, I., ... Van De Peer, Y. (2017). Single-copy genes as molecular markers for phylogenomic studies in seed plants. Genome Biology and Evolution, 9(5), 1130-1147. https://doi.org/10.1093/gbe/evx070

Linder, H. P., de Klerk, H. M., Born, J., Burgess, N. D., Fjeldså, J., \& Rahbek, C. (2012). The partitioning of Africa: Statistically defined biogeographical regions in sub-Saharan Africa. Journal of Biogeography, 39(7), 1189-1205. https://doi.org/10.1111/j.1365-2699.2012.02728.x

Marsh, B. A. (1990). The microenvironment associated with Welwitschia mirabilis in the Namib Desert. In M. K. Seely (Ed.), Namib Ecology: 25 Years of Namib Research. Transvaal Museum Monograph No.7 (pp. 149-153). Pretoria: Transvaal Museum.

Mueller-Dombois, D., \& Ellenberg, H. (1974). Aims and Methods of Vegetation Ecology. New York: Wiley.

Schulze, B. R. (1947). The climates of South Africa according to the classification of Koppen and Thornthwaite. S. Af. Geog. J., 29, 32-42.

Senut, B., Pickford, M., \& Ségalen, L. (2009). Neogene desertification of Africa. Comptes Rendus - Geoscience, 341(8-9), 591-602. https://doi.org/10.1016/j.crte.2009.03.008

Silveira, M. (1969). Pesquisa duma relação entre a variação anual da temperatura da água do mar na costa de Angola e a variação anual da precipitação no litoral e noutras regiões do território mais distantes do oceano. Memórias do Serviço Meteorológico de Angola (Vol. 6). Luanda: Serviço Meteorológico de Angola.

Skonieczny, C., Paillou, P., Bory, A., Bayon, G., Biscara, L., Crosta, X., ... Grousset, F. (2015). African humid periods triggered the reactivation of a large river system in Western Sahara. Nature Communications, 6. https://doi.org/10.1038/ncomms9751

Swinscow, T. D. V. (1972). Friedrich Welwitsch, 1806-72. A centennial memoir. Biological Journal of the Linnean Society, 4, 269-89.

Ter Braak, C.J.F., Šmilauer, P., (2012). Canoco Reference Manual and User's Guide: Software for Ordination, Version 5.0. Microcomputer Power, Ithaca, USA.

Van der Maarel, E. (2007) Transformation of Cover-Abundance Values for Appropriate Numerical Treatment - Alternatives to the Proposals by Podani. Journal of Vegetation Science, 18, $767-770$.

von Willert, D. J. (1985). Welwitschia mirabilis - new aspects in the biology of an old Plant. Advances in Botanical Research, 11(C), 157-191. https://doi.org/10.1016/S0065-2296(08)60171-8 von Willert, D. J. (1993). Can Welwitschia mirabilis have more than only two foliage leaves? South African Journal of Botany, 59(6), 639-640. https://doi.org/10.1016/S0254-6299(16)30682-2 
von Willert, D. J., Armbrüster, N., Drees, T., \& Zaborowski, M. (2005). Welwitschia mirabilis: CAM or not CAM - What is the answer? In Functional Plant Biology (Vol. 32, pp. 389-395). https://doi.org/10.1071/FP01241

Wang, X., \& Ran, J. (2014). Evolution and biogeography of gymnosperms. Mol Phylogenet Evol, 75, 24-40. https://doi.org/10.1016/j.ympev.2014.02.005

Data receção: 25/06/2018

Data aprovação: 14/11/2018 